\title{
LA DEMOCRATIZACIÓN DEL ACCESO AL TRIBUNAL PERMANENTE DE REVISIÓN DEL MERCOSUR A TRAVÉS DE LAS OPINIONES CONSULTIVAS
}

\section{A DEMOCRATIZACC̃̃O DO ACESSO AO TRIBUNAL PERMANENTE DE REVISÃO DO MERCOSUL POR MEIO DAS OPINIỐES CONSULTIVAS}

\section{Eduardo Biacchi Gomes*}

Resumen: El Protocolo de Olivos, 2002, que reglamenta el sistema de solución de controversias, estableció un interesante mecanismo de cooperación entre la jurisdicción del Tribunal Permanente de Revisión y las jurisdicciones nacionales, con la finalidad de buscar la construcción del derecho de la integración en el MERCOSUR. El sistema de las Opiniones Consultivas fue adoptado con base en la experiencia del Tribunal de Justicia (Reenvío Prejudicial) aunque los efectos de las mismas sean distintos, esta última vinculante, mientras que la primera no lo es. Aún así, el sistema de las Opiniones Consultivas, que fue recientemente reglamentado por el Supremo Tribunal Federal, es un ejemplo de cómo es posible democratizar el acceso, por parte de particulares al Tribunal Permanente de Revisión del MERCOSUR.

Resumo: O Protocolo de Olivos, 2002, que regulamenta o sistema de solução de controvérsias, estabeleceu interessante mecanismo de cooperação entre a jurisdição do Tribunal Permanente de Revisão e as jurisdições nacionais, com a finalidade de se buscar a construção do direito da integração no Mercosul. O sistema das Opiniões Consultivas foi adotado com base na experiência do Tribunal de Justiça (Reenvio Prejudicial), ainda que os efeitos das decisões sejam diversos, vez que este é vinculante, ao passo que a primeira não.Todavia, o sistema das Opiniões Consultivas, que foi recentemente regulamentado pelo Supremo Tribunal

\footnotetext{
* Pos - Doctorado por la Universidad Federal de Rio de Janeiro, con estudios realizados en la Universidad de Barcelona, Departamento de Derecho Constitucional. Doctor en Derecho de la Universidad Federal de Paraná. Profesor de Derecho Internacional y Derecho de la Integración (Pos Grado y grado) de la UniBrasil, Profesor titular de Derecho Internacional Privado de la Pontificia Universidad Católica de Paraná y Profesor de Derecho Internacional de la FACINTER. Investigador del Grupo PÁTRIAS, registrado en el Cnpq. e-mail: ebgomes@ me.com
} 
Federal, é um exemplo de como é possivel democratizar o acesso, por parte dos particulares, ao Tribunal Permanente de Revisão do MERCOSUL.

Palabras clave: MERCOSUR, Sistema de Solución de controversias, Opiniones Consultivas, Derecho de la Integración, Democracia, Jurisdicción Internacional

Palavras-chave: MERCOSUL, Sistema de solução de controvérsias, Opiniões Consultivas, Direito da Integração, Democracia, Jurisdição Internacional

\section{INTRODUCCIÓN}

Aunque la reciente historia de los factores económicos y sociales, vividos en los últimos años, principalmente en relación a la crisis mundial, puedan traer pesimismo a los procesos de formación de los procesos de integración, como en el caso de la Unión Europea o del Mercosur, debido a los nefastos efectos de la crisis económica y social que azota a los países, es importante buscar una reflexión sobre los objetivos reales de todo bloque económico, o sea: cualquier proceso de integración, en última instancia, debe adoptar políticas enfocadas a atender los intereses que competen a los Estados.

Así, tanto la Unión Europea como el Mercosur deben garantizar, eficazmente, la protección de derechos, no sólo económicos, sino principalmente los derechos sociales, fundamentales, entre otros de los nacionales de los respectivos Estados que integramos bloques. En relación al Mercosur, a pesar de que se caracterice como una Unión Aduanera imperfecta ${ }^{1}$, existen normativas que reglamentan cuestiones de interés para los nacionales de los Estados partes².

Pensar en la integración, en última instancia, es cuestionar sobre el real y efectivo papel de los Estados e instituciones del bloque, en el sentido de adoptar políticas que sirvan a los intereses de los nacionales de los Estados.

Al respecto de las peculiaridades de cada bloque económico, véase el ejemplo de la Unión Europea, donde se presenta un derecho supranacional cuyas normas tienen aplicabilidad directa sobre los ordenamientos jurídicos nacionales, mientras que en el Mercosur, regido por la intergubernamentalidad las normativas, para que se vuelvan obligatorias, necesitan ser internalizadas por los Estados; hay que destacar que la existencia de un efectivo mecanismo de solución

1 Dada la existencia del arancel externo común, que no es perfecto y contempla la lista de excepciones y régimen un régimen de adecuación. En este sentido, el Mercosur no llegó del todo a la etapa de una zona de libre comercio y ha progresado hasta la etapa de la Unión Aduanera ( Protocolo de Olivos, 1994)

2 Como se explica a continuación. 
de controversias es más que necesario para que haya seguridad jurídica en la observancia y en la aplicación de las normas emanadas de las instituciones del bloque.

La existencia de un mecanismo de cooperación, entre la instancia jurisdiccional supranacional (en el caso de la Unión Europea) e internacional (en el caso del Mercosur), es más que necesaria para dar directrices de cómo los jueces nacionales deberán interpretar y aplicar tales normativas.

En el caso del Mercosur, el Protocolo de Olivos estableció, con base en la experiencia del Tribunal de Justicia de la Unión Europea, las Opiniones Consultivas (sin carácter vinculante), materia que fue recientemente reglamentada por el Supremo Tribunal Federal, a través de la Enmienda Regimental 48, del 03 de abril de 2012 y que se traduce en un importante mecanismo de democratización del acceso a la jurisdicción del Tribunal Permanente de Revisión, por parte de los particulares.

\section{CARACTERÍSTICASDELAJURISDICCIÓNINTERNACIONAL: DEMOCRACIA MITIGADA}

El acceso a la jurisdicción internacional es distinto de aquel existente en la jurisdicción interna, debido a que en la sociedad internacional, por el hecho de ser anárquica, descentralizada, paritaria y abierta, no existe una autoridad central, o sea: un poder judicial único dotado de prerrogativas para imponer su jurisdicción y aplicar las sanciones. ${ }^{3}$. Se trata de un derecho de coordinación, en el cual las normas y las sanciones son elaboradas e impuestas por los principales sujetos del derecho internacional, que son los Estados ${ }^{4}$. En lo referente a las Organizaciones Internacionales, principalmente después de la Segunda Guerra Mundial pasaron a tener una mayor atención por parte del Derecho Internacional, a pesar de que, anteriormente, ya habían sido consideradas como sujetos de derecho internacional, como en el caso de la Organización Internacional del Trabajo, instituida por el Tratado de Versalles, 1919.

Por último, con respecto a los individuos, y sólo con carácter excepcional, pueden considerarse sujetos de derecho internacional, como es el caso de la violación de los Derechos Humanos ${ }^{5}$.

El derecho internacional clásico, tal y como fue concebido en la Paz de Westfalia, 1648, es un derecho construido por y para los Estados, siendo ellos los principales sujetos de derecho internacional y, así son

3 En el derecho internacional clásico, las sanciones se aplican de forma difusa, en este sentido, véase KELSEN. Teoria Pura do Direito. Martins Fontes: São Paulo, 2000. pp. 355 e ss.

4 En este sentido, el derecho internacional se inició con la Paz de Westfalia, 1648.

5 Los sistemas regionales de protección de los derechos humanos y el acceso a la Corte Penal Internacional. 
los legisladores y los destinatarios de las normas internacionales. Se trata de un derecho de coordinación de soberanías, en que los Estados, formalmente, se encuentran en un mismo plano de igualdad, por lo que un Estado no puede superponerse a la voluntad de otro.

En la hipótesis de cometer algún ilícito, como por ejemplo, la violación de algún tratado, la regla es la aplicación del principio secular pacta sunt servanda, aceptado en la Convención de Viena sobre derecho de los Tratados, del año 1969

En lo que se refiere al acceso a la jurisdicción internacional, la misma no se da en forma coercitiva, pues normalmente es el Estado el que acepta, voluntariamente la jurisdicción internacional ${ }^{6}$, como es el caso de la Corte Internacional de Justicia y, de acuerdo con los artículos 35 y 36 de su Estatuto, la jurisdicción no es obligatoria, no siendo necesario que los Estados que la componen, manifiesten - expresamente - su intención de aceptar la jurisdicción de la Corte, para el juzgamiento de una controversia.

Cabe señalar que de acuerdo con el Estatuto de la Corte Internacional de Justicia de La Haya, que es un órgano de controversias vinculadas a las Naciones Unidas, sólo los Estados están legitimados para demandar o ser demandado.

En otros sistemas de solución de controversias, que se rigen por el derecho internacional, como el Órgano de Solución de Controversias, vinculado a la Organización Mundial del Comercio la jurisdicción del Órgano de Solución de Controversias es obligatoria.

En ambos casos, como en otros sistemas de resolución de conflictos de derecho internacional, véase el Mercosur o NAFTA ${ }^{7}$, sólo los Estados tienen el derecho de acceso a la jurisdicción internacional, ya que son los signatarios de los tratados y los titulares de la personalidad y capacidad jurídica para demandar o ser demandado.

En palabras de Jorge Fontoura ${ }^{8}$ :

(...) el sistema de solución de diferencias de la OMC se destina, sin embargo, sólo a los Estados, en un sesgo estricto del derecho internacional público. Incluso cuando las empresas están en conflicto, sólo los estados pueden componer formalmente la disputa (...).

En cuanto a la aplicación de los tratados en la legislación nacional, los tribunales nacionales, por lo general se limitan a analizar el control

6 En este sentido, DUPUY René-Jean. O direito internacional. Almedina:Coimbra. 1993, p. 95 entiende que (...) na sociedade os Estados justapostos, a conservação da paz deve-se precisamente à sua boa vontade e à sua prudência.

7 Bloque económico en un régimen de zona de libre comercio formada por Canadá, Estados Unidos y México.

8 Embraer versus Bombardier: anatomia de um caso. GOMES Eduardo Biacchi e REIS Tarcisio Hardman.Gloalização e Comércio Internacional no direito da integração. Lex/ Aduaneiras:Rio de Janeiro, 2005. pp. 252/253. 
previo o posterior de la constitucionalidad de los tratados, sin embargo, a menudo surgen dudas de cómo el juez nacional debe interpretar y aplicar una disposición surgida de un tratado internalizado.

A pesar de que los fundamentos y presupuestos de la validez del derecho internacional son diferentes de los establecidos en el derecho interno, están cada vez más presente en los ordenamientos jurídicos internos de los Estados. Se trata de una tendencia prevista en muchas constituciones contemporáneas, con el fin de regular temas relevantes y de interés común, como los derechos humanos.

De aquí resulta el llamado déficit democrático mitigado del Derecho Internacional, porque los nacionales no poseen el debido acceso a los tribunales internacionales pues les falta el supuesto procesal elemental capacidad jurídica ${ }^{9}$ - para actuar en el foro internacional.

Como la sociedad internacional contemporánea, teniendo en cuenta los últimos acontecimientos verificados a partir de 2008 (crisis económicas en Europa y en los Estados Unidos y las respectivas protestas como: ocupación de Wall Street en Nueva York, manifestaciones en la Puerta del Sol en Madrid, protestas en Grecia, Francia, Inglaterra, sin contar con los derivados de la Primavera árabe, en el mundo islámico, es cierto que la sociedad internacional reclama cambios y el propio Derecho Internacional pasa por transformaciones.

Referidas transformaciones llevarán, indudablemente, a una mayor participación de los ciudadanos y de los propios movimientos sociales, en el poder de decisión de los Estados y la sociedad internacional pasarán a experimentar nuevos aires, con la convivencia más activa de los referidos actores en la esfera internacional (aunque la referida transformación se da de forma lenta y gradual, como es todo proceso histórico que ocurre en sociedad).

El llamado déficit democrático en cuestión es mitigado, debido a las propias características de la sociedad internacional que, en razón a sus estructuras, no permiten una mayor actuación de los individuos.

Dentro de determinados sistemas de solución de controversias, como es el caso de la Unión Europea, el particular tiene acceso a la jurisdicción supranacional y, no obstante se trate de un modelo devenido de aquellos pautados en el Derecho Internacional, se trata de un ejemplo a ser estudiado, que es el caso del Reenvío Prejudicial, conforme será visto más adelante.

En el caso del Mercosur, el Protocolo de Olivos inspirado guardadas las debidas proporciones y diferencias - en parte en la sistemática procesal del Tribunal de Justicia da Unión Europea, adoptó el sistema de las Opiniones Consultivas, instrumento procesal extremamente útil para reducir el déficit democrático existente entre el bloque económico y los particulares.

9 Se exceptúan los casos referidos a los Derechos Humanos 


\section{EL SISTEMA DE REENVÍO PREJUDICIAL EN LA UNIÓN EUROPEA Y DE LAS OPINIONES CONSULTIVAS EN EL MERCOSUR}

En la Unión Europea, bloque económico en régimen de mercado común y unión monetaria, rige un derecho específico y peculiar, que es el Derecho Comunitario, de carácter supranacional y dotado de las siguientes características: aplicabilidad directa (vale decir que la norma del bloque no necesita ser internalizada en los ordenamientos jurídicos de los Estados), primacía frente las normas nacionales (en aquellos casos en que las normas nacionales entren en conflicto con las normativas del bloque, siempre tendrán primacía las primeras) y la uniformidad en la interpretación y en la aplicación de las normativas ${ }^{10}$.

Relativamente a esta última característica, vale destacar que los jueces nacionales son, al mismo tiempo, jueces supranacionales, dado que, en aquellas materias de competencia de las Instituciones del bloque, como las normativas poseen aplicabilidad directa y primacía frente a los ordenamientos jurídicos nacionales, ellas pueden ser invocadas por los particulares en las jurisdicciones nacionales. Así, siempre que sean provocados para dirimir cuestiones que involucren normativas de la Unión Europea, deberán asegurar la primacía en su aplicación.

En la hipótesis de que existan dudas, por parte del juez nacional sobre la interpretación y la aplicación de las referidas normativas, ella podrá ser suscitada para el Tribunal de Justicia de la Unión Europea, a través del Reenvío Prejudicial, que es un mecanismo procesal que posibilita uniformidad en la interpretación y aplicación del Derecho de la Unión Europea, por parte de los jueces nacionales.

Se trata de un mecanismo de cooperación entre las instancias nacionales y la supranacional, cuya decisión, en relación a la interpretación o a los propios efectos de la norma supranacional, vincula al juez nacional y produce efecto entre las partes, pudiendo servir de jurisprudencia en casos similares ${ }^{11}$.

El reenvío prejudicial permite a las instancias jurisdiccionales nacionales aplicar de forma homogénea el Derecho de la Unión Europea en las 27 (veintisiete) jurisdicciones nacionales. Además, el Tribunal de Justicia de la Unión Europea, en este sentido, únicamente dará su pronunciamiento respecto a la correcta interpretación y aplicación de la norma, en determinado caso en concreto. En ningún caso se da la supresión de instancia, o sea: la competencia para juzgar la controversia continuará siendo de la instancia jurisdiccional nacional, aún ${ }^{12}$, en el

10 En este sentido, ver, GOMES Biacchi Eduardo. Blocos Econômicos e Solução de Controvérsias, 3a. Ed. Juruá:2010. pp. 146 a 148.

11 En este sentido, ver CAMPOS João Mota de. Manual de Direito Comunitário 2a. Edição. Curitiba:Juruá, 2008. pp. 307 e ss.

12 Conforme CAMPOS João Mota de e CAMPOS João Luiz Mota de. Contencioso 
caso específico, su juzgamiento estará condicionado a la interpretación emanada del fallo del Tribunal de Justicia de la Unión Europea.

El procedimiento es facultativo en los procesos de instancias inferiores $y$, por tanto, pasibles de reformulación por los tribunales superiores, y obligatorio cuando el proceso esté en trámite en la última instancia recursiva.

En el sistema intergubernamental del Mercosur, el mecanismo de cooperación utilizado es el de las Opiniones Consultivas que, a ejemplo del modelo supranacional del Reenvío Prejudicial, es aplicada cuando las partes o el propio juez nacional de la causa, posee dudas en cuanto a la aplicación e interpretación de una norma del bloque, en el caso concreto. Sin embargo, existen determinadas diferencias entre ambas: a) la decisión de la Opinión Consultiva no es vinculante, lo cual implica que, no obliga al juez nacional. b) En la sistemática del Protocolo de Olivos, los particulares no pueden, directamente, plantear la cuestión, por ende procede a tramitarse por los Tribunales Superiores de los Estados y, c) la instancia jurisdiccional nacional no es obligada a aceptar el pedido de Opinión Consultiva ${ }^{13}$.

La materia está contenida en el Protocolo de Olivos, $2002^{14}$ y su Reglamento ${ }^{15}$. En Brasil es competente para reenviar las opiniones consultivas el Supremo Tribunal Federal ${ }^{16}$; en Argentina, la Corte Suprema de Justicia de la Nación ${ }^{17}$; en Paraguay ${ }^{18}$ y en Uruguay ${ }^{19}$, la Corte Suprema de Justicia. Las competencias podrán ser delegadas para otros tribunales de apelación, con jurisdicción nacional.

La tramitación y el envío de las Opiniones Consultivas se encuentran reglamentados en la Decisión Mercosur CMC 02/2007 y, básicamente, se resume en lo siguiente:

Art. 4 - La solicitud de opiniones consultivas será presentada por escrito, y, de acuerdo con el Artículo 5 de la Decisión CMC No 37/03, y contendrá los siguientes elementos:

- a) Exposición de los actos y del objeto de la solicitud;

- b) Descripción de las razones que motivaron la solicitud; y

Comunitário. Curitiba:Juruá, 2008, p. 154, “o Tribunal Comunitário não pode, pois, tentar orientar o juiz nacional quanto à aplicação do Direito Comunitário, sob pena de ultrapassar sua competência.

13 En este sentido, ver GOMES Eduardo Biacchi. Protocolo de Olivos. Alterações no sistema de solução de controvérsias do Mercosul e perspectivas, pp. 671/684, in. BAPTISTA, Luiz Olavo e Mazzuoli, Valério de O (Orgs). Doutrinas Essenciais de Direito Internacional. Editora RT:São Paulo, 2012.

14 Artigo $3^{\circ}$.

15 Mercosur CMC/DEC 37/03

16 Reglamentado por la Enmienda Regimental 48 de 2012 del STF.

17 Reglamentado por la Acordada 13/2008 de la Corte Suprema de Justicia de la Nación

18 Reglamentada por la Acordada 549 de 2008 de la Corte Suprema de Justicia

19 Reglamentado por la Acordada 7604 de 2007 de la Suprema Corte de Justicia 
- c) Indicación precisa de la Normativa MERCOSUR en causa.

(....)

Las opiniones consultivas solicitadas referirán exclusivamente a la interpretación jurídica del Tratado de Asunción, del Protocolo de Ouro Preto, de los protocolos y acuerdos celebrados en el ámbito del Tratado de Asunción, de las Decisiones del CMC, de las Resoluciones del GMC y de las Directrices del GMC.

Las opiniones consultivas solicitadas necesariamente deben estar vinculadas a las causas pendientes en los litigios Poder Judicial o de los órganos judiciales - administrativas del Estado Parte solicitante.

Art. 5 -Tribunales Superiores de los Estados Partes deberán enviar las solicitudes de opiniones consultivas al TPR, a través de su Secretaría (ST), con copia a la Secretaría del MERCOSUR, a los efectos del artículo 11 del presente Reglamento, y para los otros Tribunales Superiores designados por los Estados Partes.

(.....)

Art. 7 - El TPR solamente conocerá en la solicitud presentada cuando:

a) La solicitud proceda de uno de los Tribunales Superiores designados por los Estados Partes;

b) El pedido esté formulado de acuerdo con lo dispuesto en el Artículo 4 de este Reglamento;

c) La cuestión en causa no sea objeto de procedimiento de solución de controversias en curso sobre la misma cuestión.

En los casos en que no se verificaren los requisitos de admisibilidad arriba previstos, el TPR denegará la solicitud, informando inmediatamente al Tribunal solicitante.

Art. 8 - Admitida la solicitud de la opinión consultiva, el Presidente del Tribunal coordinará con los demás integrantes del TPR la designación del árbitro responsable que se encargará de la coordinación de la respuesta, de acuerdo con lo dispuesto en el Artículo 6.3 de la Decisión CMC No 37/03. Por tanto, se llevará en cuenta la actuación de los árbitros en casos similares. En caso de no llegar a un consenso para a designación, se efectuará el sorteo previsto referido en el Artículo 6.3. Art. 9 - Los Coordinadores Nacionales del GMC podrán, en un plazo de quince días contados a partir de la notificación de recibimiento de una solicitud de opinión consultiva, conforme al Artículo 6, enviar al TPR, por intermedio de la ST, sólo con fines informativos, sus eventuales consideraciones sobre el tema objeto de la solicitud de opinión consultiva.

Art. 10 - La admisión o recusación de una solicitud enviada al TPR y las opiniones consultivas emitidas por este órgano serán enviadas directamente al Tribunal Superior solicitante y notificadas a todos los Estados Partes, por intermedio de la ST, con copia a la Secretaria del MERCOSUR y a los demás Tribunales Superiores indicados por los 
Estados Partes.

Art. 11 - Los gastos derivados de la emisión de opiniones consultivas solicitadas por los Tribunales Superiores de Justicia, tales como los honorarios, los gastos de traslado, viáticos de los integrantes del Tribunal Permanente de Revisión y los demás gastos que puedan derivar de su tramitación, serán costeados por el Estado Parte al cual pertenezca el Tribunal Superior de Justicia peticionario.

Conforme aclara Luciane Klein Vieira ${ }^{20}$, en el sistema de las Opiniones Consultivas del Mercosur, los requisitos para la presentación del pedido, aunque sea necesario el cumplimiento de determinados requisitos, carece de mayores formalismos, en relación a la presentación del pedido, materia ya reglamentada por las jurisdicciones nacionales de los Tribunales Superiores de los Estados ${ }^{21}$.

Importante es destacar, sobre este acceso al sistema de las Opiniones Consultivas, el pensamiento de Perotti ${ }^{22}$, según el cual en ausencia de reglamentación en cuanto al acceso al Tribunal Permanente de Revisión, violaría el derecho fundamental de los jurisdicionados de los Estados Partes del Mercosur en busca de la mejor interpretación y aplicación de las referidas normativas. Conforme aduce Perotti, mencionado derecho fundamental está previsto en los "pactos internacionales sobre derechos humanos, como la Declaración Universal de los Derechos Humanos (arts. 8 a 10), Convención Americana sobre Derechos Civiles y Políticos (arts. 8, inciso 1 y 25, inciso 1) y en el Pacto Internacional sobre Derechos Civiles y Políticos (arts. 2, inciso 3, a líneas "a" y "b" y 14, inciso 1).

Se puede constatar, que al día de hoy, el derecho internacional y el propio derecho de la integración merecen ser repensados en la óptica del individuo. En este sentido, conforme apunta GOMES"3. "Varios factores que pueden ser destacados para su resurgimiento (...) como la consolidación de los bloques económicos (...)”. Repensar los procesos de integración y el propio Mercosur, a partir de la vertiente de la persona humana es una medida que necesaria para que los objetivos establecidos

20 VIEIRA Luciane Klein. Interpretación y aplicación uniforme del Derecho de la Integración. Unión Europea, Comunidad Andina y Mercosur. B\&F:Buenos Aires, 2011. p. 95.

21 La Enmienda Regimental 48 de 2012 del Supremo Tribunal Federal, establece en el artículo 354-l que poseen legitimidad para requerir el envío de solicitud da Opinión consultiva, cualquiera de las partes o el propio juez de la causa. De acuerdo con el artículo 354-J, la solicitud deberá contemplar los siguientes requisitos: a) exposición de los hechos y del objeto de la decisión, b) descripción de las razones que motivaron la decisión, c) indicación precisa de la Normativa Mercosur respecto a la cual se realiza la consulta, d) la indicación del juicio y de la acción en que (fue) originada la solicitud.

22 PEROTTI Alejandro D. Tribunal Permanente de Revisión y Estado de Derecho en el Mercosur. Marcial Pons:Buenos Aires., 2008. pp. 107 e 108. Original en español y traducción libre del autor.

23 GOMES Eduardo Biacchi. Tratados Internacionais. pp. 115 e 116. in. BAPTISTA, Luiz Olavo e Mazzuoli, Valério de O (Orgs). Doutrinas Essenciais de Direito Internacional. Editora RT:São Paulo, 2012. 
en sus tratados fundacionales no se pierdan en meros discursos (fantasiosos) económicos y comerciales.

Nada más correcto que democratizar el acceso a la jurisdicción del Tribunal Permanente de Revisión para los individuos, a través de las Opiniones Consultivas, de manera a garantizar la efectiva protección de los derechos fundamentales.

El avance auspicioso demostrado por el Supremo Tribunal Federal al, finalmente, reglamentar tal cuestión, como forma de democratizar el acceso a aquella jurisdicción.

\section{DEMOCRATIZACIÓN DEL ACCESO A LA JURISDICCIÓN DEL TRIBUNAL PERMANENTE DE REVISIÓN}

Especialmente en relación a la democracia y los derechos fundamentales, el Mercosur presenta resultados, a través de decisiones y políticas que son adoptadas por sus socios.

Desde su creación el MERCOSUR anheló consolidarse como un mercado común, con la libre circulación de bienes, personas, servicios y capitales y, así, la integración concentra otros objetivos, de aquellos meramente económicos y comerciales, conforme previsión del Tratado de Asunción, 1991.

Como forma de alcanzar los objetivos del Mercosur, es necesario que los tribunales nacionales garanticen la eficacia en el cumplimento de las normativas, inclusive en relación a las normas de derecho interno, esto porque, con la globalización es mayor el flujo migratorio, etc., y se vuelve cada vez más necesario que el derecho de la integración pase a preocuparse por temas sensibles a los intereses de los individuos, como los derechos fundamentales y la democracia.

La aplicación de las referidas normas y políticas, por parte de los Estados, ya es una realidad, como es el caso del Parlamento del MERCOSUR, el cual, aunque no posea competencias legislativas, puede auxiliar la observancia de los referidos derechos y ejerce un papel fundamental en su fiscalización.

Las Opiniones Consultivas del Mercosur vienen a ocupar un importante espacio dentro del derecho de la integración del Mercosur, de modo de facilitar la interpretación y la aplicación de las normativas del bloque, visto que uno de los principales impedimentos existentes dentro del bloque, para su evolución es el desconocimiento, por parte de los abogados, juristas, jueces, etc., sobre sus normas y contenido.

Sobre el tema, expone la circular emanada del Tribunal Permanente de Revisión de $n^{\circ}$ 119/2012, de fecha 16 de abril del corriente año ${ }^{24}$ :

Las opiniones consultivas consisten en un procedimiento para la

24 http://www.tprmercosur.org/pt/index.htm (acesso em 04.05.2012). 
interpretación o aplicación del derecho del MERCOSUR, en el caso concreto, tendiente a una uniforme aplicación. (...)

La instrumentalización del acceso de los jueces nacionales al procedimiento de Opiniones Consultivas se da a partir de reglamentos internas. La Argentina tiene el procedimiento de Opiniones Consultivas reglamentada por la Acordada 13/08 CSJN, el Paraguay por la Acordada 549 CJJ y el Uruguay por la Circular 86/2007 SCJ (todas disponibles en www.tprmercosur.org).

El Brasil, a través de la Enmienda Regimental 48 del STF, de fecha 03 de abril del corriente año, reglamentó el procedimiento, de forma que, ahora, todos los jueces nacionales pueden solicitar Opiniones Consultivas al Tribunal Permanente de Revisión.

Es oportuno destacar que en el llamado caso de las papeleras, entre la República Oriental del Uruguay y la República da Argentina, incluso en la instancia del TPR (Laudo Arbitral 02/2006) los árbitros se manifestaron sobre temas relacionados a los derechos fundamentales y democracia.

En lo que respecta a la interpretación de los Tribunales argentino y brasileño sobre las normativas MERCOSUR que versan sobre derechos humanos (fundamentales en el plano interno) y democracia, se mencionan el Tercer Informe sobre la aplicación del Derecho del MERCOSUR por parte de los Magistrados nacionales de los Estados Partes publicado por la Secretaría del bloque económico, en el año de $2005^{25}$.

En aquel documento se pudo constatar el posicionamiento avanzado de la jurisdicción de la República de Argentina, que reconoce, como obligatoria la Declaración Socio-laboral del MERCOSUR, de 1998, y fundamenta sus decisiones en base al referido documento emanado de sus instituciones. En una de sus decisiones, señaló que la práctica de la empresa violó los derechos humanos y fundamentó su decisión con base en el artículo 10 de la Declaración Socio-laboral del MERCOSUR, que asegura a los empleados y a los empleadores la libertad de negociar y de celebrar las convenciones y acuerdos colectivos, de acuerdo con la ley nacional ${ }^{26}$.

En otra decisión, emanada por la Justicia Laboral de la República de Argentina, el juez se valió, y citó el Juez Capón Filas, sobre la importancia de la aplicación judicial de las Convenciones Fundamentales de la OIT y de la propia Declaración Socio Laboral del MERCOSUR, entendiendo que esta última, por fuerza de lo dispuesto en la Constitución Argentina

25 http://www.mercosur.org.uy/innovaportal/file/2179/1/tercer\%20informe\%20final.pdf (acesso em 31.10.2010).

26 CNTrab., Federación Operária Ceramista de la República Argentina c/Cámara de Fabricantes de Artefactos Sanitários de Cerámica s/juicio sumaríssimo. proc. n. 24810/03, sentença 58.031, 05.05.2005. 
en su artículo 75.22 (que asegura que los tratados poseen grado de jerarquía por encima de la ley), tendría grado de jerarquía supralegal ${ }^{27}$.

Resáltese, por otra parte, la Decisión emanada de la Justicia Nacional del Trabajo 38 la República de Argentina, que eleva la Declaración Socio-laboral del MERCOSUR, a una norma de carácter preceptivo y vinculante $\mathrm{y}$, por tanto, no permitiría derogación en contrario, por tratarse de una norma de ius cogens. Asevera que referido instrumento se traduce en una norma de derechos humanos que, por tanto, integra el rol de derechos fundamentales del trabajador, a través del cual todos los Estados tienen el deber de observarla, siendo que las legislaciones nacionales deben sujetarse a sus disposiciones ${ }^{28}$.

Del Supremo Tribunal Federal, pueden ser destacados algunos fallos emblemáticos que analizaron temas alusivos a las normativas MERCOSUR:

Acto por incumplimiento del Principio Fundamental 101, que cuestionaba la importación de neumáticos recauchutados101. Figuró como relatora la Ministra Carmen Lúcia, juzgado en 11.3.2009.

Orden de Seguridad Preventiva 26600, con el fin de suspender la tramitación del proyecto de resolución del Congreso Nacional 03/2007, relativa a la representación brasileña en Parlamento del MERCOSUR. Relatora, Ministra Carmen Lúcia, juzgado en 19.11.07.

Homologación de Sentencias Extranjeras $n^{\circ}$ 7101, Relator Ministro Maurício Correa, juzgado en 14.11.2003

Concretamente la Enmienda Regimental 48 del Supremo Tribunal Federal establece en su artículo $7 \mathrm{mo}$, inciso VIII que es de competencia del Plenario, en las sesiones administrativas. Decidir administrativamente, sobre el envío de las Opiniones Consultivas, mediante previo y necesario juicio de admisibilidad del pedido y su pertinencia. El pedido de envío es relatado por el Presidente del Supremo Tribunal Federal. Recibida la solicitud el Presidente del Supremo Tribunal Federal iniciará, a través de proceso virtual, la colecta de votos de los Ministros o, si lo cree conveniente, enviará copias a los demás Ministros antes de la sesión administrativa ${ }^{29}$ designada para la determinación de la presencia de los requisitos de aplicación y su pertinencia procesal ${ }^{30}$.

De forma a contemplar la Resolución Mercosur que reglamenta el Trámite de las Opiniones Consultivas, el Reglamento del Supremo

27 JLC n. 1. PARTIÑO Daniel Esteban c/ Alicia Álvarez y otros s/ind. proc. 15.309, sentença n. $107,14.06 .2005$.

28 JNTrab. Bergara Juan Ramón c/Piso Uno SRL s/despido, proc. n. 3.767/2004, 09/09/2005. 29 Por tratarse de una decisión a ser votada en sesión administrativa, de acuerdo con lo que establece la Constitución Federal, artículo 93, incisos IX y X, las sesiones serán públicas y las decisiones motivadas.

30 Artículo 354-K Enmienda Regimental 48 de 2012. 
Tribunal Federal reafirma lo expuesto en ese instrumento, especialmente en relación a la necesidad de que la solicitud de Opinión Consultiva verse sobre la aplicación de una normativa Mercosur en curso en el tribunal brasileño, cuya decisión, de ser dictada por el Tribunal Permanente de Revisión, no posee efecto vinculante.

Así, la democratización al acceso al Tribunal, a través del sistema de las Opiniones Consultivas, posibilita al particular y a los propios magistrados de instancias inferiores buscar la mejor forma de interpretación y de aplicación de las normativas Mercosur. No se busca, en este artículo, hacer alusión a la adopción del sistema de Reenvío Prejudicial, que es propio del derecho de la Unión Europea. Aunque, referido mecanismo de cooperación entre la instancia del Tribunal Permanente de Revisión y las jurisdicciones nacionales, permitiría una mayor consciencia en relación a la importancia del derecho de la integración del Mercosur.

\section{CONSIDERACIONES FINALES}

La República Federativa del Brasil, durante mucho tiempo, estuvo del lado contrario de la correcta interpretación y aplicación de las normas del derecho internacional, resquicio quizá, del triste período de la dictadura militar. En los últimos años el derecho internacional experimenta un momento especial, porque su conocimiento es cada vez más solicitado, tanto en el ámbito académico, como por los profesionales del derecho junto con los tribunales.

Gran ejemplo de ello es la propia jurisprudencia del Supremo Tribunal Federal en temas relacionados a los derechos humanos en que ha pasado a entender que los referidos tratados (ratificados antes de la Enmienda Constitucional 45/04) poseen un grado de jerarquía supralegal (aunque esta no sea la mejor comprensión doctrinal que siempre ha abogado por la equiparación de los tratados de derechos humanos al grado de jerarquía constitucional), de acuerdo con lo dispuesto en el $\$ 2^{\circ}$ del artículo $5^{\circ}$ de la Constitución Federal.

Lamentablemente el poder judicial brasileño no posee la tradición de examinar cuestiones derivadas de la interpretación y de la aplicación de las normativas Mercosur, al contrario del poder judicial argentino que, de forma corriente, son examinados temas que involucran el derecho de la integración del Mercosur.

Importante es observar que de las tres Opiniones Consultivas, emanadas del Tribunal Permanente de Revisión, ninguna fue solicitada por el Supremo Tribunal Federal, porque recién ahora el procedimiento fue reglamentado, mientras que en las Cortes argentina, paraguaya y uruguaya, la materia ya estaba debidamente enmarcada en normas ${ }^{31}$.

31 www.mercosur.int (acceso 07 de mayo de 2012) 
En lo que se refiere a los rumbos de la integración regional la Constitución de la República Federativa del Brasil aún no avanzó en términos concretos, notoriamente porque, diferente de las Constituciones de sus aliados argentinos y paraguayos, en donde se admite la supranacionalidad ${ }^{32}$, en nuestra Constitución el hecho no está contemplado.

No obstante todas las críticas que puedan ser hechas, tanto por los juristas, economistas, sociólogos, políticos, empresarios, en relación al proceso de integración del Mercosur, no hay como negar que él es una realidad y que políticas son hechas y aplicadas por los Estados, las cuales repercuten directamente en la esfera legal de los ciudadanos.

La existencia de un marco normativo, como es el caso del Mercosur, es más que necesario para garantizar la debida seguridad jurídica en el cumplimiento de las referidas políticas por los Estados. La correcta aplicación de esas políticas, por parte de los Estados, por cierto depende de una eficaz actuación del Poder Público y la propia fiscalización del Poder Judicial, en el sentido de velar por el interés público, principalmente en aquellas cuestiones referidas a los derechos fundamentales y democracia.

Como el derecho de la integración del Mercosur es una realidad, nada más beneficioso que los jueces nacionales apliquen las normativas del bloque. La reglamentación del Sistema de las Opiniones Consultivas, por el Supremo Tribunal Federal, representa esta realidad, la propia democratización del acceso al poder judicial, para fines de aplicación de las normas Mercosur.

\section{RFERENCIAS BIBLIOGRÁFICAS}

CAMPOS João Mota de (2008) Manual de Direito Comunitário. 2a. ed. Curitiba: Juruá.

CAMPOS João Mota de e CAMPOS João Luiz Mota de (2008) Contencioso Comunitário. Curitiba: Juruá.

DUPUY René-Jean (1993) O direito internacional. Almedina: Coimbra. GOMES Biacchi Eduardo (2010) Blocos Econômicos e Solução de Controvérsias. 3a. ed. Juruá.

GOMES Eduardo Biacchi (2012) "Protocolo de Olivos. Alterações no sistema de solução de controvérsias do Mercosul e perspectivas". In: BAPTISTA Luiz Olavo e MAZZUOLI Valério de Olivera (orgs.) Doutrinas Essenciais de Direito Internacional. São Paulo: Editora RT, p. 671/684. GOMES Eduardo Biacchi (2012) “Tratados Internacionais". In: BAPTISTA Luiz Olavo e MAZZUOLI Valério de Olivera (orgs.) Doutrinas Essenciais de Direito Internacional. São Paulo: Editora RT, p. 115 e 116.

32 En este sentido, la mayoría de las Constituciones de los Estados miembros de la Unión Europea admite la supranacionalidad. 
GOMES Eduardo Biacchi e REIS Tarcisio Hardman (2005) Gloalização e Comércio Internacional no direito da integração. Rio d janeiro: Lex/ Aduaneiras.

KELSEN Hans (2000) Teoria Pura do Direito. São Paulo: Martins Fontes. PEROTTI Alejandro D. (2008) Tribunal Permanente de Revisión y Estado de Derecho en el Mercosur. Buenos Aires: Marcial Pons.

VIEIRA Luciane Klein (2011) Interpretación y aplicación uniforme del Derecho de la Integración. Unión Europea, Comunidad Andina y Mercosur. Buenos Aires: B\&F. 